\title{
Risk Analysis On Behavior For Software Projects Based On Game Theory
}

\author{
Ying $\mathrm{Qu}^{1, \mathrm{a}}, \mathrm{XinHui} \mathrm{Li}^{2, \mathrm{~b}}$ \\ ${ }^{12}$ School of Economics and Management, \\ Hebei University of Science and Technology \\ Shijiazhuang, 050018, China, \\ aQuying1973@126.com, b15100137330@163.com
}

Keywords: Game theory; Conflict analysis; Asymmetric information; Software project actors; Risk Analysis

\begin{abstract}
Conflict analysis is a model of the game theory. This paper aims at analyzing the relationship among software projects actors in the game by using conflict analysis models to identify the risk factors. The behaviors of the subjects including software developers, agents, users and other stakeholders of software projects are analyzed from the perspective of stakeholders to find out the potential risks in it. Based on the as ymmetric information theory and game theory, the results showed that the developers will damage the interests in hiding technical information of agents and users under the asymmetric information in a balanced outcome of the game. Therefore, the agents need to look for software professionals to assess the qualifications of the project and the users need to take pre-agreement to avoid such problems.
\end{abstract}

\section{Introduction}

With the continuous promotion of information construction, more and more software projects are applied in our life. Therefore, in order to reduce the risk of software project, improving the successful rate of software projects to strengthen the risk management of software project has important significance. Risk management is very important in the process of software project development. If reasonable or not, it will directly affect the success or failure of the software project. Currently, discussions on the is sue are in full swing in the theorists. Identifying the risk factors has two main focus areas. First, defining the risk from the type of resource, such as personnel, finance, technology, time, information, and knowledge. Foreign scholars Cristina (2012) discussed the impact of software project risk caused by the technology and a new system and provided the decision support for the software project risk managers[1]. Xie Gang (2006) applied the life-cycle theory to the problems of software project bidding risk aversion from the perspective of time to tender for risk identification and proposed suggestions and countermeasures to avoid the risk of bidding[2]. Second, analyzing the risk factors from the project management process, such as requirements analysis, schedule, quality, cost and other perspectives. Pan Meisen (2007) established a software project risk assessment model about the analysis of needs and predicted the software project risk level from the perspective of requirements analysis[3].

It is worth noting that the existing articles are often more concerned about the objective risk factors and focus on the point of management. However, the root of project risks is generated by the project actors which dominates the trend of project development. The research on software project risk is still in its infancy. Currently, Domestic scholars have tried to apply the theory of actors risk to the field of engineering project risk. Ren Yulong (2004) established an incentive information model based on the theory of asymmetric information and analyzed the problems of commissioned agency relationship [4]. He Xudong (2012) emphasized the importance of the project participants and believed that the success of the project depended on the project stakeholders subjectivity, which is very significant in the field of engineering[5]. This paper attempts to take advantage of conflict analysis model to analyze the risk of 
software projects involved in stakeholders' decision-making based on the asymmetric information. By extracting the risk caused by the stakeholders' behaviors of software projects provides the better solutions for the stakeholders in the software projects.

\section{The game analysis model of software project actors}

This paper applies the conflict analysis model which belongs to game theory to predict the result of the conflict situation and analyze the process[6]. Conflict analysis, as an analytic method, can solve many problems that are difficult to express in the quantitative way and maximizes the use of information[7]. The basic model of conflict analysis can be represented as equation(1).

$$
\mathrm{C}=\{\mathrm{N}, \mathrm{E}, \mathrm{P}, \mathrm{UI}\}
$$

Among them:

$\mathrm{N}$ : The Participants in the conflict, $\mathrm{N}=\{1,2 \cdots \cdots \mathrm{n}\}$;

E: All possible situations set in the current situation. The feasible situation is represented by a vector 0 -1. It will give a vector code for each situation;

P: the preference ordering set that participants focused on each feasible situation;

UI: a unilateral improved conflict set of each participant according to the preference ordering.

This paper studies the conflict among the software developers, software agents and users. It does not involve other stakeholders. Assumptions as follows:

1) The model of conflict analysis is used in project setting stage.

2) Business negotiations between software project participants including software developers, software agents and potential users have begun. There is a strong willingness to cooperate for the participants.

3) This paper chooses a bundled software or plug-ins as example.

4) Players' strategy will continue to change in the direction of their most advantageous choice. Software developers have intangible technical information. However, the software agents and users don't obtain the technical information of software project.

\section{Modeling of software project actors and analysis}

According to the actual situation of software project setting stage, the players, feasible solutions, viable situation and stabilize the situation of this model are showed as follows:

The analysis of feasible situation for the players. In the course of the conflict, each player can choose their own strategies based on selection scheme after the other participants [8]. The set every participant selected constructs an outcome. Theoretically, there are 25=32 kinds of conflicts situation. But we should exclude the situation that does not meet the actual situation. The situation finally gets 13 feasible situations. As is shown in Table 1: 
Table 1 Each participant's feasible conflict situation in the softw are project setting stage

\begin{tabular}{ccccccccccccccc}
\hline \multicolumn{1}{c}{ Players } & Strategy & \multicolumn{10}{c}{ Situation } \\
\hline & Hiding information & 0 & 1 & 1 & 1 & 1 & 0 & 0 & 0 & 0 & 0 & 0 & 0 & 0 \\
$\begin{array}{c}\text { Developers } \\
\text { (D) }\end{array}$ & $\begin{array}{c}\text { Semi-concealed } \\
\text { Information }\end{array}$ & 0 & 0 & 0 & 0 & 0 & 1 & 1 & 1 & 1 & 0 & 0 & 0 & 0 \\
& $\begin{array}{c}\text { Confessing } \\
\text { Information }\end{array}$ & 0 & 0 & 0 & 0 & 0 & 0 & 0 & 0 & 0 & 1 & 1 & 1 & 1 \\
& Sales promotion & 0 & 1 & 1 & 0 & 0 & 1 & 1 & 0 & 0 & 1 & 1 & 0 & 0 \\
Agents(A) & Agreement & 0 & 1 & 0 & 1 & 0 & 1 & 0 & 1 & 0 & 1 & 0 & 1 & 0 \\
Users (U) & & 0 & 1 & 2 & 3 & 4 & 5 & 6 & 7 & 8 & 9 & 10 & 11 & 12
\end{tabular}

In table 1, software project developers" program is that "Hiding the information of software technology" , "Semi-concealed the software technical information" and "Confessing the software technical information". Indeed, once software project developers adopt the program in "Hiding the information of software technology" . They can't select the other two programs. Therefore, a combination of a program is able to represent all combinations of programs. For brevity, the rest is omitted here.

Preference order in the situation. According to the principle that they should maximize the interests, it orders the situation in the vector code [9]. From left to right, it will be the best countermeasure to the least optimal countermeasures. For software projects agents, they hope software developers confess the technical information and estimate the ability to gain returns according to the information that project developers provide. Then they select promotion and hope to reach an agreement with the developer and user and then benefit from it. Therefore, the program 9 ranked in the first position. Agents' preference order is summarized based on the principle of maximizing profit in Table 2 .

Table 2 The preference rankings in the software project agents' situation

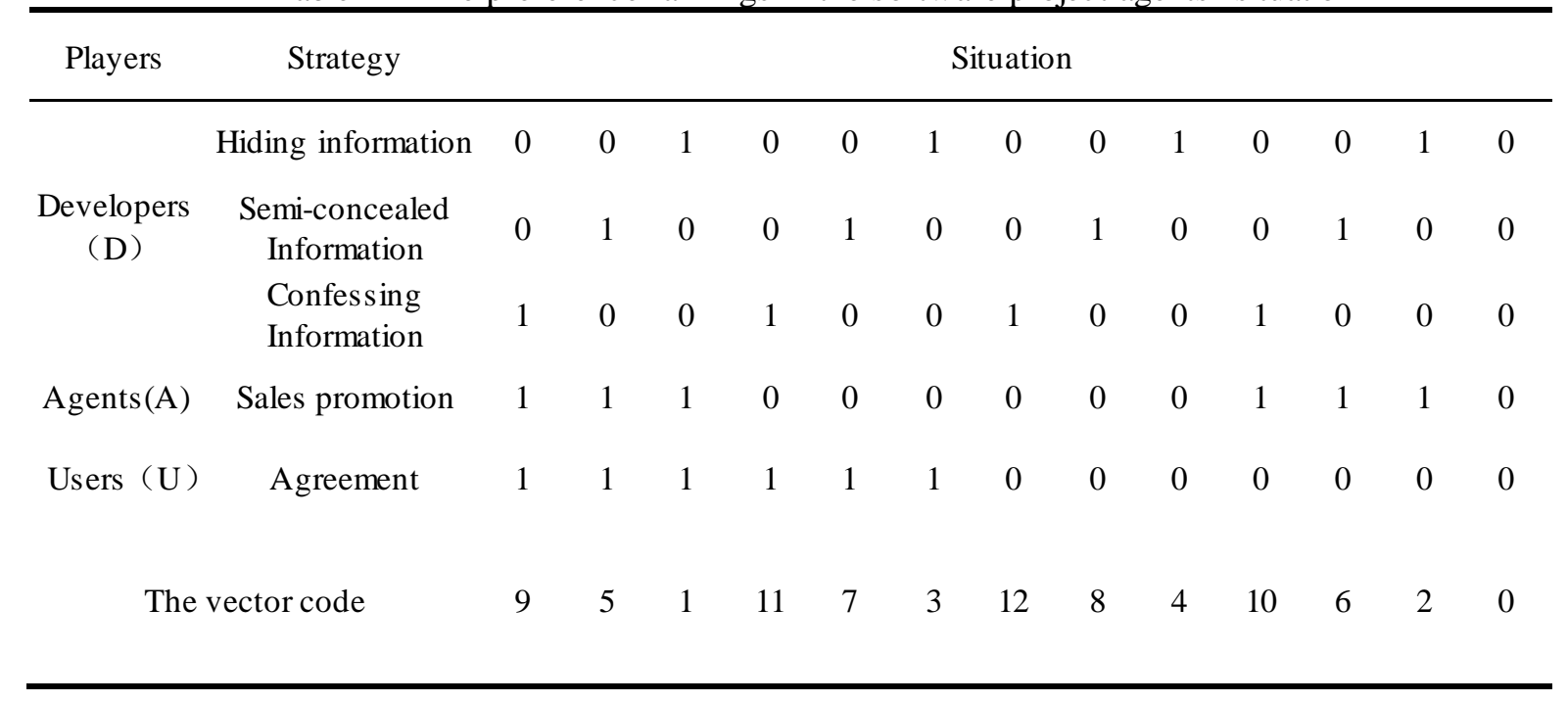

Definitely, software project developers prefer "Hiding Technical Information" to maximize their own interests especially for the bundled software or plug-in. obviously; it is additional revenue for software developers. The software project developers expect the user to reach an agreement. The conclusion of software project developers' preference order is summarized in table 3 . 
Table 3 The preference rankings in the software project developers' situation

\begin{tabular}{|c|c|c|c|c|c|c|c|c|c|c|c|c|c|c|}
\hline \multirow[t]{2}{*}{ Players } & \multirow{2}{*}{$\begin{array}{c}\text { Strategy } \\
\text { Hiding } \\
\text { information }\end{array}$} & \multicolumn{13}{|c|}{ Situation } \\
\hline & & 1 & 0 & 0 & 1 & 0 & 0 & 1 & 0 & 0 & 1 & 0 & 0 & 0 \\
\hline \multirow[t]{2}{*}{$\begin{array}{l}\text { Developers } \\
\text { (D) }\end{array}$} & $\begin{array}{l}\text { Semi-concealed } \\
\text { Information }\end{array}$ & 0 & 1 & 0 & 0 & 1 & 0 & 0 & 1 & 0 & 0 & 1 & 0 & 0 \\
\hline & $\begin{array}{l}\text { Confessing } \\
\text { Information }\end{array}$ & 0 & 0 & 1 & 0 & 0 & 1 & 0 & 0 & 1 & 0 & 0 & 1 & 0 \\
\hline Agents (A) & Sales promotion & 1 & 1 & 1 & 1 & 1 & 1 & 0 & 0 & 0 & 0 & 0 & 0 & 0 \\
\hline Users（U） & Agreement & 1 & 1 & 1 & 0 & 0 & 0 & 1 & 1 & 1 & 0 & 0 & 0 & 0 \\
\hline \multicolumn{2}{|c|}{ The vector code } & 1 & 5 & 9 & 2 & 6 & 10 & 3 & 7 & 11 & 4 & 8 & 12 & 0 \\
\hline
\end{tabular}

For software projects users, they hope software developers confess the technical information and show some technical information of software projects in order to avoid the moral hazard problems. Finally the users expect to cooperate with software developers. The specific sorting results are shown in table 4 above.

Table 4 The preference rankings in the software project users' situation

\begin{tabular}{|c|c|c|c|c|c|c|c|c|c|c|c|c|c|c|}
\hline \multirow[t]{2}{*}{ Players } & \multirow[t]{2}{*}{ Strategy } & \multicolumn{13}{|c|}{ Situation } \\
\hline & & 0 & 0 & 0 & 0 & 0 & 0 & 0 & 0 & 1 & 1 & 1 & 1 & 0 \\
\hline \multirow[t]{2}{*}{$\begin{array}{l}\text { Developers } \\
\text { (D) }\end{array}$} & $\begin{array}{l}\text { Semi-concealed } \\
\text { Information }\end{array}$ & 0 & 1 & 0 & 1 & 0 & 1 & 0 & 1 & 0 & 0 & 0 & 0 & 0 \\
\hline & $\begin{array}{l}\text { Confessing } \\
\text { Information }\end{array}$ & 1 & 0 & 1 & 0 & 1 & 0 & 1 & 0 & 0 & 0 & 0 & 0 & 0 \\
\hline Agents(A) & Sales promotion & 1 & 1 & 0 & 0 & 1 & 1 & 0 & 0 & 1 & 1 & 0 & 0 & 0 \\
\hline Users（U) & Agreement & 1 & 1 & 1 & 1 & 0 & 0 & 0 & 0 & 1 & 0 & 1 & 0 & 0 \\
\hline \multicolumn{2}{|c|}{ The vector code } & 9 & 5 & 11 & 7 & 10 & 6 & 12 & 8 & 1 & 2 & 3 & 4 & 0 \\
\hline
\end{tabular}

Stability analysis. Stability analysis is conducted according to table 1-4. A balance outcome can be got from all possible outcomes. Specific steps are showed as follows:

1) Determining unilaterally improvements $(U I)$. Assuming that the software project user does not change their policy, the developers unilaterally improve its strategy to make their situation better [10]. For software project developers, there is a unilateral improvement, if they change their strategy $q$ to make changes to $q^{\prime}$. And $q$ is superior to $q^{\prime}$. Then UI can be noted.

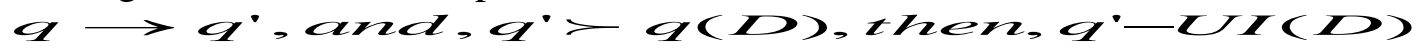

Here, taking software developers' strategy 5 (01011) as example. When the agency chooses strategy "sales promotion" and the users select the "agreement" which is shown in Table 3. The developers hope to improve the strategy to 1(10011). For developers, the situation 1 is ranked before the situation 5. Therefore, the situation 1 is a unilateral improved situation than 5. The situation 1 has no any unilateral improved situation. It is a reasonable situation which is called $r$. And so on, it can be drawn from other unilateral improvement situation.

2) Determining the basic individual steady state. Developers' collection of stabilizing situation is $(1,2,4,0)$. Software project Agents' collection of stabilizing situation is $(9,5,1,3,12,8,4,0)$. However, 
software project user' collection of stabilizing situation is $(9,5,11,7,8,1,3,0)$. Among them, software project participants' common collection of stabilizing situation is (0), (1) . Because the situation 0 (00000) represented no action for any party. It does not meet the actual research situation and should be discarded. Therefore, 1 (10011) is the stabilizing situation. We should discard the rest of the global stability of the situation which does not meet the reality. By analyzing the stability of the outcomes in the Table 2-4, the results are shown in table 5.

Table 5 Stability Analysis

\begin{tabular}{|c|c|c|c|c|c|c|c|c|c|c|c|c|c|}
\hline developers (D) & \multicolumn{13}{|c|}{ Developers' (D) preference rankings } \\
\hline Stability of the players & $\mathrm{r}$ & & & $\mathrm{r}$ & & & & & & $\mathrm{r}$ & & & $\mathrm{r}$ \\
\hline Preference ordering & 1 & 5 & 9 & 2 & 6 & 10 & 3 & 7 & 11 & 4 & 8 & 12 & 0 \\
\hline \multirow{2}{*}{ Unilateral improvements } & & 1 & 5 & & 1 & 6 & 1 & 1 & 7 & & 4 & 8 & \\
\hline & & & 1 & & & 1 & & & 1 & & & 4 & \\
\hline $\operatorname{agents}(\mathrm{A})$ & \multicolumn{13}{|c|}{ Agents'(A) preference rankings } \\
\hline Stability of the players & $\mathrm{r}$ & $\mathrm{r}$ & $\mathrm{r}$ & & & $\mathrm{r}$ & $\mathrm{r}$ & $\mathrm{r}$ & $\mathrm{r}$ & & & & $\mathrm{r}$ \\
\hline Preference ordering & 9 & 5 & 1 & 11 & 7 & 3 & 12 & 8 & 4 & 10 & 6 & 2 & 0 \\
\hline Unilateral improvements & & & & 9 & 5 & & & & & 12 & 8 & 4 & \\
\hline users (U) & \multicolumn{13}{|c|}{ Users' (U) preference rankings } \\
\hline Stability of the players & $\mathrm{r}$ & $\mathrm{r}$ & $\mathrm{r}$ & $\mathrm{r}$ & & & & $\mathrm{r}$ & $\mathrm{r}$ & & $\mathrm{r}$ & & $\mathrm{r}$ \\
\hline Preference ordering & 9 & 5 & 11 & 7 & 10 & 6 & 12 & 8 & 1 & 2 & 3 & 4 & 0 \\
\hline & & & & & 9 & 5 & 11 & & & 1 & & 3 & \\
\hline
\end{tabular}

\section{Summary}

The above analysis showed that software developers and users of the game had only one equilibrium 1 in the process. Eventually, IT project developers will conceal technical information. The agents and users will be in a disadvantage position.

Therefore, it is recommended when sales agencies and developers attempt to sign a contract, sales agencies should look for software professionals to assess the qualifications of the project. Sales agencies and users are necessary to understand the relevant laws and regulations in order to protect their own benefits. The software project users and software project developers must develop a good agreement in advance. It can effectively prevent software project developers from hiding the core technology of information software to circumvent users' needs. Once the users found that software project de velopers choose half hidden strategy, they should timely feedback and ask for information. If necessary, they should take legal means to safeguard their own interests. This paper established the conflict analysis model of software projects among actors to discover the project risks. It not just fits the reality of a common phenomenon in the software industry, but it provides the best solutions to software project developers, software project and user agents. It's a new idea to identify risks in the field of software project risk from the aspect of subject behavior based on the theory of asymmetric information and conflict analysis.

\section{Acknowledgment}

This paper is supported by the project from national natural Foundation of China (71301044). It also gets help from the project of Heibei Education Department of China (201418, ZD2014027). 


\section{References}

[1] Cristina Lopez, Jose L. Salmeron. Risk response strategies for supporting practitioners decision making in software projects[J]. Procedia Technology, Vol. 5, pp. 437-444, 2012.

[2] Xiegang, Zhang jinlong. Based on IT projects to avoid the risk of the whole life cycle of bidding. Research Management[J]. Vol. 27, No.3, pp. 97-102, 2006.

[3] Pan meisen, Xiong qi. Based on SVM software risk assessment model of the requirements analysis[J]. Computer Engineering. Vol.33, No.12, pp. 78-81, 2007.

[4] Ren yulong,Wu guosheng. Economic Analysis of Project Principal Parts[J]. Chongqing University News, Vol.27,No.4, pp.142-145,2004.

[5] He xudong. The Behavioral Risk of Projects[J]. Economic and Management Research, Vol. 2, pp. 27-30, 2012.

[6] Lazaros Sarigiannidis, Prodromos D. Quality vs risk: An investigation of their relationship in software development projects[J]. International Journal of Project Management, Vol. 32, No.6, pp. 1073-1082,2014.

[7] Walsh Kenneth R,Schneider Helmut. The role of motivation and risk behavior in software are development success[J]. Information Research, Vol.7, No.3, pp.27-36, 2002.

[8] Sandra Miranda Neves, Carlos Eduardo Sanches da Silva. Risk mangement in software projects through Knowledge Management techniques: Cases in Brazilian Incubated Technology-Based Firms[J]. International Journal of Project Management, vol. 32, No.1, pp. 125-138, 2014.

[9] Vahid Khodakarami, Abdollah Abdi. Project cost risk analysis: A Bayesian networks approach for modeling dependencies between cost items[J]. International Journal of Project Management. Vol.32, No.7, pp.233-1245, 2014.

[10] Xiang pengcheng,Kong deping. New Perspective on Risk Research Project-The main Behavioral Project risk[J]. Construction Economy, Vol. 3, No.329, pp. 72-75, 2010. 